\title{
Tissue-Engineered Decellularized Allografts for Anterior Cruciate Ligament Reconstruction
}

Yamin Li*€, MD, Tonghe Zhu*€, MD, Liren Wang*€, MD, Jia Jiang*, MD, Guoming Xie*, MD, Xiaoqiao Huangfu*, MD, Shikui Dong*§, MD, Jinzhong Zhao*§, MD

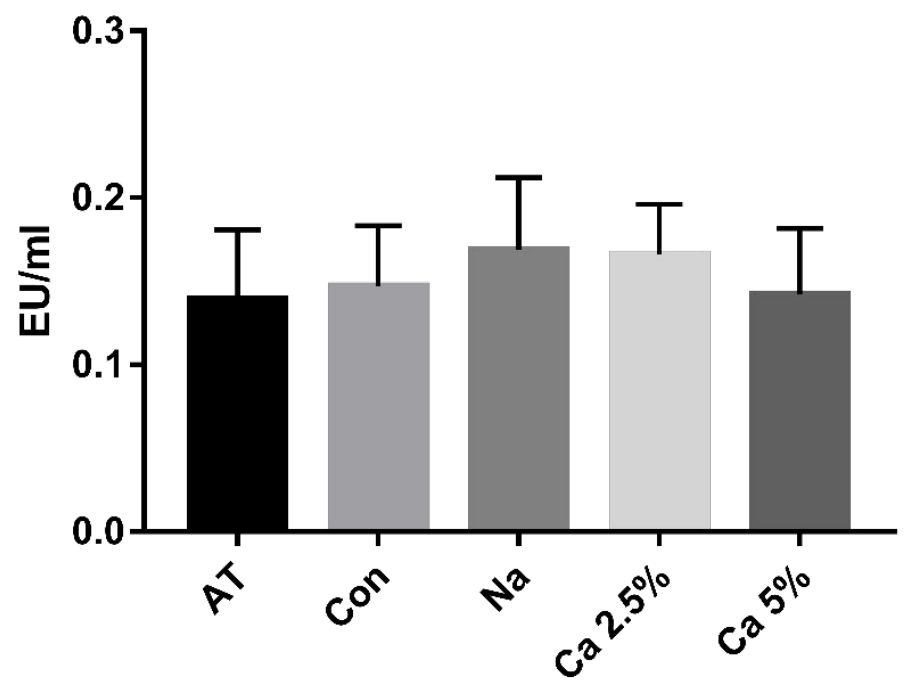

Figure S1. The results of endotoxin content of four DAs. The control group was unneutralized decellularized allograft. 


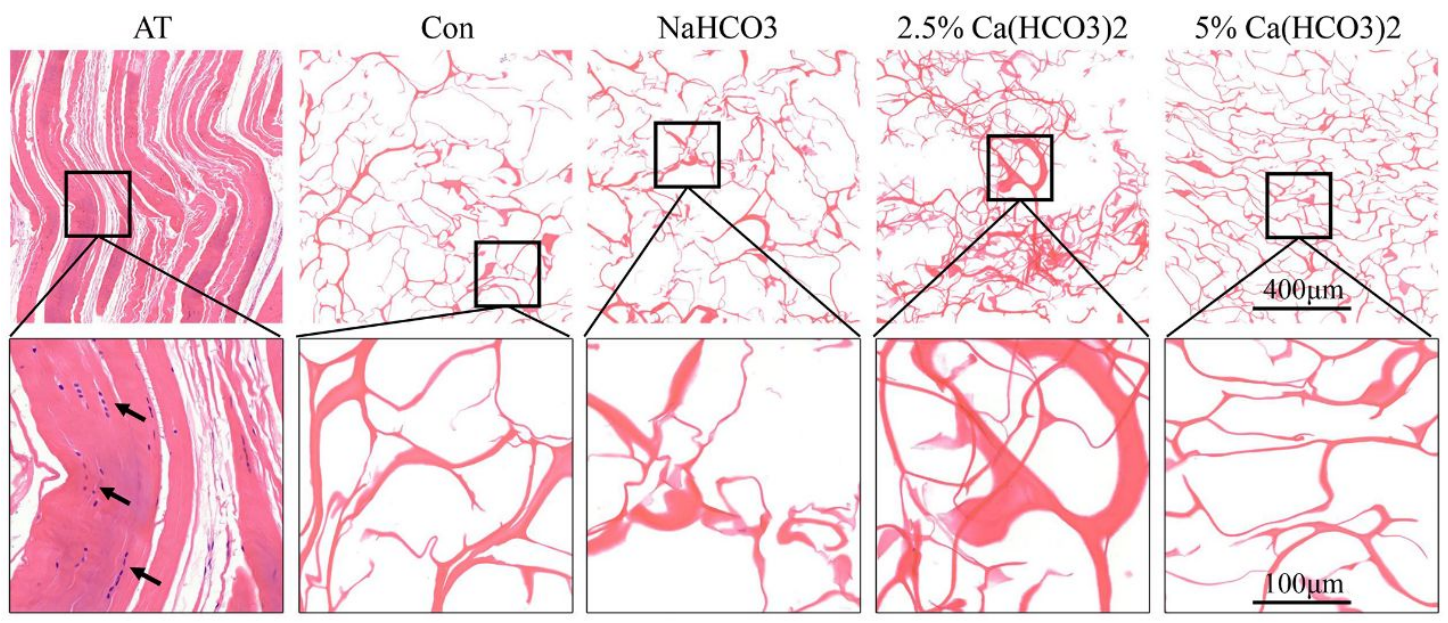

Figure S2. HE staining of four kinds of DAs. The control group was unneutralized decellularized allograft. 


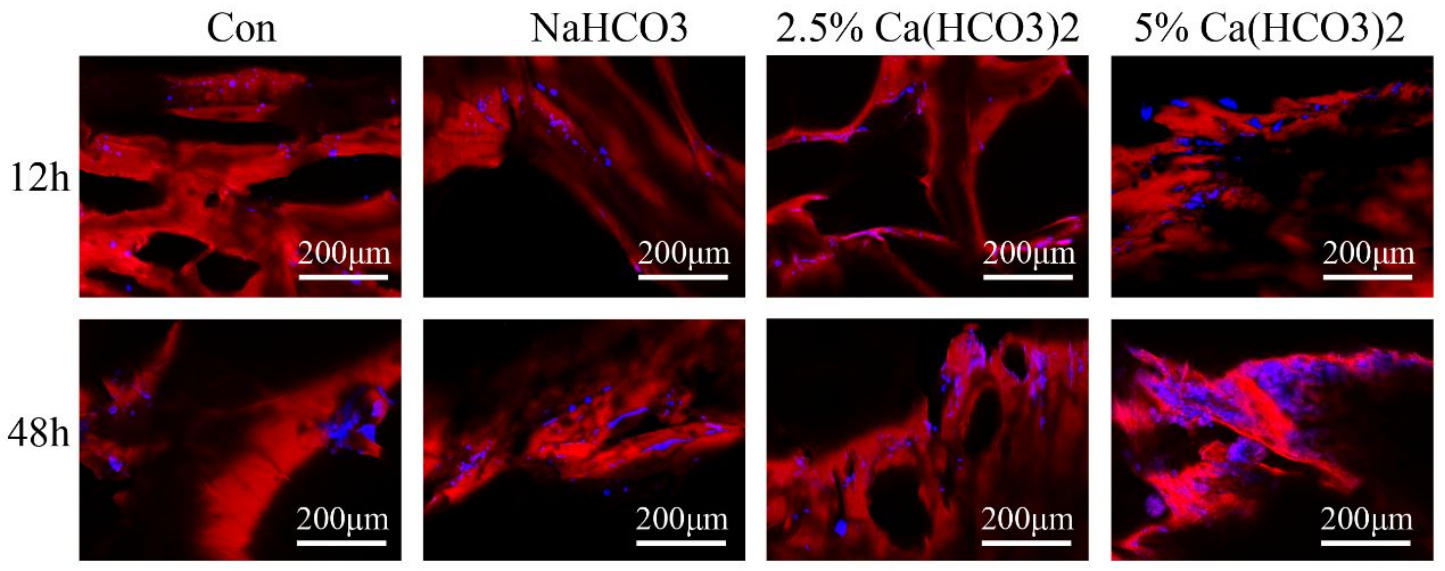

Figure S3. Immunofluorescent staining of the morphology of TSPCs attaching on four DAs.

\begin{tabular}{|l|l|l|}
\hline Item & Description & Score \\
\hline Integration at the & Complete & 2 \\
\cline { 2 - 3 } insertion site with & Minor disruption $(<50 \%$ of area) & 1 \\
\cline { 2 - 3 } surrounding tissue & Major disruption ( $>50 \%$ of area) & 0 \\
\hline Stiffness of the & Normal compared to posterior cruciate ligament & 2 \\
\hline
\end{tabular}




\begin{tabular}{|l|l|l|}
\hline \multirow{2}{*}{ tendon graft } & Softer & 1 \\
\cline { 2 - 3 } & Very soft & 0 \\
\hline \multirow{2}{*}{ Appearance of the } & Smooth & 2 \\
\cline { 2 - 3 } articular surface & Fine fronds & 1 \\
\cline { 2 - 3 } Color the & Severe fronds & 0 \\
\cline { 2 - 3 } articular surface & Gloomy white & 2 \\
\cline { 2 - 3 } & Yellow bone & 1 \\
\hline Total & & 8 \\
\hline
\end{tabular}

Table S1. Macroscopic evaluation of ACL reconstruction. 


\begin{tabular}{|c|c|c|}
\hline Item & Description & $\begin{array}{l}\text { Scor } \\
\text { e }\end{array}$ \\
\hline \multirow[t]{4}{*}{ Cell Infiltration } & Low levels of infiltration around the graft & 0 \\
\hline & Gradual infiltration from the periphery to the center & 1 \\
\hline & Obvious cell infiltration inside the graft & 2 \\
\hline & Loss of cell density inside the graft & 3 \\
\hline \multirow{4}{*}{$\begin{array}{l}\text { New ves } \\
\text { formation }\end{array}$} & No new vessel formation & 0 \\
\hline & Low levels of new vessel formation & 1 \\
\hline & Large levels of new vessel formation & 2 \\
\hline & Decreasing levels of new vessel formation & 3 \\
\hline \multirow{4}{*}{$\begin{array}{l}\text { Collagenous } \\
\text { alignment }\end{array}$} & No high collagen birefringence & 0 \\
\hline & Slight high collagen birefringence $(<30 \%)$ & 1 \\
\hline & Moderate high collagen birefringence $(<70 \%)$ & 2 \\
\hline & Abundant high collagen birefringence $(\geq 70 \%)$ & 3 \\
\hline Total & & 9 \\
\hline
\end{tabular}

Table S2. Histological evaluation of graft remodeling in ACL reconstruction 


\begin{tabular}{|c|c|c|}
\hline Item & Description & Score \\
\hline \multirow{2}{*}{$\begin{array}{l}\text { Cell migration } \\
\text { towards the tendon- }\end{array}$} & Slight $(<25 \%)$ & 0 \\
\hline & Moderate $(25 \%$ to $50 \%)$ & 1 \\
\hline \multirow[t]{2}{*}{ bone interface } & Substantial $(50 \%$ to $75 \%)$ & 2 \\
\hline & Intense $(75 \%$ to $100 \%)$ & 3 \\
\hline \multirow{4}{*}{$\begin{array}{l}\text { Sharpey's } \\
\text { formation }\end{array}$} & None $(0 \%$ in tendon-bone interface $)$ & 0 \\
\hline & Slight ( $0 \%$ to $30 \%$ in tendon-bone interface) & 1 \\
\hline & Moderate $(30 \%$ to $60 \%$ in tendon-bone interface) & 2 \\
\hline & Abundant ( $60 \%$ to $100 \%$ in tendon-bone interface) & 3 \\
\hline Fibrocartilage & Slight fibrocartilage formation $(<30 \%)$ & 0 \\
\hline formation & Moderate fibrocartilage formation ( $30 \%$ to $60 \%$ ) & 1 \\
\hline Calcification & Abundant fibrocartilage formation $(>60 \%)$ & 2 \\
\hline accumulation & Calcification accumulation occurring & 3 \\
\hline Total & & 9 \\
\hline
\end{tabular}

Table S3 Histological evaluation of tendon-bone healing in ACL reconstruction 